\title{
Song Bu Li Decoction, a Traditional Uyghur Medicine, Protects Cell Death by Regulation of Oxidative Stress and Differentiation in Cultured PC12 Cells
}

\author{
Maitinuer Maiwulanjiang, ${ }^{1}$ Kevin Y. Zhu, ${ }^{1}$ Jianping Chen, ${ }^{1}$ Abudureyimu Miernisha, ${ }^{1}$ \\ Sherry L. Xu, ${ }^{1}$ Crystal Y. Q. Du, ${ }^{1}$ Kitty K. M. Lau, ${ }^{1}$ Roy C. Y. Choi, ${ }^{1}$ Tina T. X. Dong, \\ Haji A. Aisa, ${ }^{2}$ and Karl W. K. Tsim ${ }^{1}$ \\ ${ }^{1}$ Division of Life Science and Centre for Chinese Medicine, The Hong Kong University of Science and Technology, \\ Clear Water Bay Road, Hong Kong \\ ${ }^{2}$ Xinjiang Key Laboratory of Plant Resources and Natural Products Chemistry, Xinjiang Technical Institute of Physics and Chemistry, \\ Chinese Academy of Sciences, Urumqi 830011, China
}

Correspondence should be addressed to Karl W. K. Tsim; botsim@ust.hk

Received 21 May 2013; Revised 2 August 2013; Accepted 26 August 2013

Academic Editor: Paul Siu-Po Ip

Copyright (C) 2013 Maitinuer Maiwulanjiang et al. This is an open access article distributed under the Creative Commons Attribution License, which permits unrestricted use, distribution, and reproduction in any medium, provided the original work is properly cited.

\begin{abstract}
Song Bu Li decoction (SBL) is a traditional Uyghur medicinal herbal preparation, containing Nardostachyos Radix et Rhizoma. Recently, SBL is being used to treat neurological disorders (insomnia and neurasthenia) and heart disorders (arrhythmia and palpitation). Although this herbal extract has been used for many years, there is no scientific basis about its effectiveness. Here, we aimed to evaluate the protective and differentiating activities of SBL in cultured PC12 cells. The pretreatment of SBL protected the cell against tBHP-induced cell death in a dose-dependent manner. In parallel, SBL suppressed intracellular reactive oxygen species (ROS) formation. The transcriptional activity of antioxidant response element (ARE), as well as the key antioxidative stress proteins, was induced in dose-dependent manner by SBL in the cultures. In cultured PC12 cells, the expression of neurofilament, a protein marker for neuronal differentiation, was markedly induced by applied herbal extract. Moreover, the nerve growth factor(NGF-) induced neurite outgrowth in cultured PC12 cells was significantly potentiated by the cotreatment of SBL. In accord, the expression of neurofilament was increased in the treatment of SBL. These results therefore suggested a possible role of SBL by its effect on neuron differentiation and protection against oxidative stress.
\end{abstract}

\section{Introduction}

Traditional Uyghur medicine (TUM), one of the main medicinal systems in central Asia, is based on four humors: fire, air, water, and earth, which generates four different body fluids: blood, phlegm, yellow bile, and black bile [1]. The main ingredients of TUM are flowers, seeds, fruits, minerals, and animal compartments. According to the TUM theory, diseases or impairments are resulted from imbalance between the four body fluids. TUM herbal formulation could regulate the balance of body fluids and cure diseases [2]. Song $\mathrm{Bu}$ Li decoction (SBL), a TUM formula described in Sherhi Alkanun by Emam Durdin during AD 840-1212, consists of only one herb named Nardostachyos Radix et Rhizoma (NRR, a root and rhizome of Nardostachys jatamansi). Recently, SBL has been used to treat neurological disorders (insomnia and neurasthenia) and heart disorders (palpitation and arrhythmia) in Xinjiang of China. According to ancient method of preparations of TUM [2], two methods of SBL preparation are commonly used in Xinjiang: (i) NRR is boiled with water, and the vapor generated is being collected as the volatile components of NRR. Condensed vapor and extracted water are mixed and (ii) NRR is boiled in water and filtered, and only the water extract is being used for treatment. Both preparation methods of SBL generate a problem of quality control and efficacy. 
Neurasthenia is defined as a condition with symptoms of fatigue, forgetfulness, sleepless, anxiety, and depressed $\operatorname{mood}[3,4]$, and the pathogenesis of neurasthenia still remains unknown [5]. During the brain development, neuronal stem cells undergo a stage called neurogenesis in which immature neurons grow, differentiate, and survive. However, for patients with neurasthenia and depression, the normal neurogenesis would be impaired, that is, the inability for neurons to differentiate normally. Amongst different causes of neuronal cell death, reactive oxygen species (ROS) mediated oxidative stress is one of the major origins of many neurological disorders [6-8]. The excess generation of ROS damages cells by peroxidizing lipids and disrupting structural proteins, enzymes, and nucleic acids $[9,10]$. In defending the stress, antioxidant response element (ARE), located upstream of various genes, could regulate the expression of antioxidative stress proteins [11-13].

Neuronal differentiation of PC12 cells, mediated by nerve growth factor (NGF), shows the morphological change of cells possessing neurites. In addition, the neuronal differentiation could be determined biochemically by analyzing the expression of neurofilaments (NFs) that are the major structural components of differentiated neurons $[14,15]$. Three mammalian neurofilament subunits, NF68, NF160, and NF200 are believed to form heterodimers in making the structural domain of neurites [16]. The differentiation status of neuron is also a critical parameter of neuron survival.

Having the questions of SBL efficacy under two distinct preparative methods, we aimed to establish quality control parameters of the herbal preparation and to reveal the role of SBL in preventing neuronal cell death. Chemical fingerprint and quantitation of ingredients, including ferulic acid, linarin, and volatile oil, were developed for quality control. In the bioassay, the role of SBL in preventing tertButyl hydroperoxide- (tBHP-) induced cell death as well as the gene activation of antioxidative stress proteins was determined. Lastly, the length of neurites and the expression of neurofilaments were determined in $\mathrm{PC} 12$ cells under the treatment of SBL.

\section{Materials and Methods}

2.1. Plant Materials and Preparation of SBL. NRR, the root and rhizome of $N$. jatamansi, was purchased from Hong Kong herbal market (Wong Chak Kee Co.). The authentication of plant material was performed by Dr. Tina T. X. Dong according to their morphological characteristics. The voucher specimens were deposited in the Centre for Chinese Medicine R\&D at The Hong Kong University of Science and Technology. The herb NRR was minced and soaked in water in the proportion of $1: 10(\mathrm{w} / \mathrm{v})$ overnight. The mixture was submitted to hydrodistillation in a Clevengertype apparatus for 4 hours. Water extract and volatile oil of NRR were obtained at the same time. Volatile oil was dried over anhydrous sodium and stored at $-20^{\circ} \mathrm{C}$. The resulting water extract was filtered, vacuum-dried to powder, and kept at $-20^{\circ} \mathrm{C}$. This extract was considered as an NRR extract. The extraction efficiency reached over $95 \%$ within 4 hours.
For SBL preparation, $1 \mathrm{~g}$ of dried NRR powder was dissolved in $20 \mathrm{~mL}$ DMSO and sonicated for $30 \mathrm{~min}$. The extract was centrifuged at $13,200 \mathrm{rpm}$ at $4^{\circ} \mathrm{C}$ for $5 \mathrm{~min}$, and $170 \mu \mathrm{L}$ of volatile oil was added onto the supernatant as the final SBL decoction.

2.2. Chemicals and Reagents. Ferulic acid (>98\%), tert-Butyl hydroperoxide (tBHP) (>98\%), tert-Butylhydroquinone (tBHQ) (>98\%), 3-(4,5-dimethylthiazol-2-yl)-2,5-diphenyl tetrazolium bromide (MTT) (>98\%) were purchased from Sigma Chemical Co. (St. Louis, MO, USA). Linarin (>98\%) was kindly provided by Testing Laboratory for Chinese Medicine (Hong Kong, China). HPLC-grade acetonitrile and methanol were purchased from Merck (Darmstadt, Germany). Ultra-pure water was prepared from a Milli-Q purification system (Millipore, Molsheim, France).

2.3. GC-MS Analysis. Agilent 7000 GC-MS series system (Waldbronn, Germany) equipped with an Agilent 7890A gas chromatography and GC-QQQ Mass Hunter workstation software was adopted. The extract was separated in an Agilent HP-5MS capillary column $(250 \mu \mathrm{m} \times 30 \mathrm{~m} \times 0.25 \mu \mathrm{m})$ with controlled temperature at $100^{\circ} \mathrm{C}$ in the initial stage, and the temperature was adjusted to $280^{\circ} \mathrm{C}$ at the rate of $5^{\circ} \mathrm{C} / \mathrm{min}$. Pulsed splitless injection was conducted by injecting $1 \mu \mathrm{L}$ of the sample extract. Helium was used as carrier gas at a flow rate of $2.25 \mathrm{~mL} / \mathrm{min}$; nitrogen was used as the collision gas at a flow rate of $1.5 \mathrm{~mL} / \mathrm{min}$. The spectrometer was operated in a full-scan electron-impact (EI) mode, and the ionization energy was $70 \mathrm{eV}$. The inlet and ionization source temperatures were $250^{\circ} \mathrm{C}$ and $230^{\circ} \mathrm{C}$, respectively. The solvent delay time was $3.5 \mathrm{~min}$. Retention indices of all compounds were determined according to the Kovats method using $n$ alkanes (Sigma) as standards. Identification of the volatile compounds was confirmed by comparing the mass spectra with the Kovats retention indices.

2.4. HPLC-DAD Analysis. HPLC-DAD analysis was conducted with an Agilent HPLC 1200 series system (Agilent Waldbronn, Germany), which was equipped with a degasser, a binary pump, an autosampler, a diode array detector (DAD), and thermo-stated column compartment. Chromatographic separation was carried out on an Intersil C18 column (particle size $5 \mu \mathrm{m}, 4.6 \times 250 \mathrm{~mm}$ ) with water (as solvent A) and acetonitrile (as solvent B) as the mobile phase at flow rate of $1.0 \mathrm{~mL} / \mathrm{min}$ at room temperature using the following gradient program: 0-20 min, isocratic gradient 19$19 \%$ (B); 20-25 min, linear gradient $19-25 \%$ (B); 25-45 min, linear gradient $25-35 \%$ (B); and 45-55 min, linear gradient $35-55 \%$ (B). A preequilibration period of $10 \mathrm{~min}$ was used between each run. The injection volume was $10 \mu \mathrm{L}$. The UV detector wavelength was set to $334 \mathrm{~nm}$ with full spectral scanning from 190 to $400 \mathrm{~nm}$.

2.5. PC12 Cell Culture. Pheochromocytoma PC12 cells, a cell line derived from rat adrenal medulla, were obtained from American Type Culture Collection (ATCC, Manassas, VA) and maintained in Dulbecco's modified Eagle's medium 
(DMEM) supplemented with 6\% fetal bovine serum, 6\% horse serum, 100 units $/ \mathrm{mL}$ penicillin, and $100 \mu \mathrm{g} / \mathrm{mL}$ of streptomycin in a humidified $\mathrm{CO}_{2}(7.5 \%)$ incubator at $37^{\circ} \mathrm{C}$. Culture reagents were from Invitrogen (Carlsbad, CA). For the differentiation assay, cultured PC12 cells were serum starved for 4 hours in DMEM supplemented with $1 \%$ fetal bovine serum, $1 \%$ horse serum, and penicillin-streptomycin, and then they were treated with the SBL and/or other reagents for 72 hours.

2.6. MTT and ROS Formation Assay. PC12 cell viability was assayed by reduction of MTT [3-(4,5-dimethylthiazol2-yl)-2,5-diphenyl tetrazolium bromide] reagent. Cells $(2 \times$ $10^{4}$ cells/well) were plated in 96-well plate and pretreated with different concentrations of SBL and/or other reagents for 24 hours. Then, the cells were treated with $150 \mu \mathrm{M}$ tBHP for 3 hours. The cultures were then treated with MTT solution for 1 hour, and the optical density was measured using spectrophotometer at $570 \mathrm{~nm}$. The determination of ROS level in cell cultures was performed according to Zhu et al. [17]. In brief, cultured PC12 cells in a 96-well plate were pretreated with different concentrations of SBL and/or other reagents for 24 hours and labeled by $100 \mu \mathrm{M} \mathrm{DCFH-DA}$ (Sigma) in HBSS for 1 hour at room temperature. Cultures were then treated with $100 \mu \mathrm{M}$ tBHP for 1 hour. The amount of intracellular tBHP-induced ROS formation was detected by fluorometric measurement with excitation at $485 \mathrm{~nm}$ and emission at $530 \mathrm{~nm}$ (Spectra max Gemini XS, Molecular Devices Crop., Sunnyvale, CA).

2.7. DNA Construction and Transfection. The pGL4.37[luc2P/ARE/Hygro] vector contains four copies of an antioxidant response element (ARE; $5^{\prime}$-TGACnnnGCA$\left.3^{\prime}\right)$ that drives transcription of the luciferase reporter gene luc2P (Photinus pyralis). Luc2P is a synthetically-derived luciferase sequence with humanized codon optimization that is designed for high expression and reduced anomalous transcription. The luc $2 P$ gene contains hPEST, a protein destabilization sequence, which allows luc $2 P$ protein levels to respond more quickly than those of luc2 to induce transcription. Cultured PC12 cells were transfected with pARE-Luc (Promega, Fitchburg, WI) by Lipofectamine 2000 (Invitrogen) according to the manufacturer's instructions. The transfection efficiency was $\sim 60 \%$, as determined by another control plasmid having $\beta$-galactosidase, under a cytomegalovirus enhancer promoter.

2.8. Luciferase Activity. PC12 cells, cultured in 24-well plate (1 $\times 10^{5}$ cells/well), were treated with SBL and/or other reagents for 24 hours. Afterward, the medium was aspirated, and cultures were washed by ice-cold PBS. The cells were lysed by a buffer containing $0.2 \%$ Triton X-100, $1 \mathrm{mM}$ dithiothreitol, and $100 \mathrm{mM}$ potassium phosphate buffer $(\mathrm{pH} 7.8)$ at $4^{\circ} \mathrm{C}$. Followed by centrifugation at $13,200 \mathrm{rpm}$ for $10 \mathrm{~min}$ at $4^{\circ} \mathrm{C}$, the supernatant was collected and used to perform luciferase assay (Tropix Inc., Bedford, MA); the activity was normalized by amount of protein and the activity of $\beta$-galactosidase (a control plasmid).
2.9. Polymerase Chain Reaction (PCR) Analysis. PC12 cells were treated with SBL and/or other reagents for 24 hours. Total RNAs were isolated by TRIzol reagent (Invitrogen) and reverse-transcribed by Moloney Murine Leukemia Virus Reverse Transcriptase (Invitrogen) according to the manufacturer's instruction. Real-time PCR was performed by using SYBR green master mix and ROX reference dye according to the manufacturer's instruction (Applied Bioscience, Foster City, CA). The primers were as follows: $5^{\prime}$-GAC CTT GCT TTC CAT CAC CAC CGG- $3^{\prime}$ and $5^{\prime}$-GTA GAG TGG TGA CTC CTC CCA GAC-3' for NAD(P)H quinone oxidoreductase (NQO1; $241 \mathrm{bp}$ ); $5^{\prime}$-CCT GCT GTG TGA TGC CAC CAG ATT TT- $3^{\prime}$ and $5^{\prime}$-TCT GCT TTT CAC GAT GAC CGA GTA CC-3' for glutamate-cysteine ligase modulatory subunit (GCLM; 197 bp); 5' -CGT GGA CAC CCG ATG CAG TAT TCT G- $3^{\prime}$ and $5^{\prime}$-GGG TCG CTT TTA CCT CCA CTG TAC T-3' for glutamate-cysteine catalytic subunit (GCLC; 261 bp); $5^{\prime}$-CCT GGG CAT CTG AAA CCT TTT GAG AC$3^{\prime}$ and $5^{\prime}$-GCG AGC CAC ATA GGC AGA GAG C- $3^{\prime}$ for glutathione $S$-transferase (GST; $180 \mathrm{bp}$ ). Glyceraldehyde 3phosphate dehydrogenase (GAPDH) was used as an internal control in all cases, and its primer sequence was $5^{\prime}$-AAC GGA TTT GGC CGT ATT GG- $3^{\prime}$ and $5^{\prime}$-CTT CCC GTT CAG CTC TGG G-3' (657 bp). SYBR green signal was detected by Mx3000ptm multiplex quantitative PCR machine (Applied Bioscience, Foster City, CA). The transcript levels were quantified by using $\Delta \Delta C_{t}$ value method [18]. Calculations were done using the $C_{t}$ value of GAPDH to normalize the $C_{t}$ value of target genes in each sample to obtain the $\Delta C_{t}$ values which were used to compare among different samples. PCR products were analyzed by gel electrophoresis and melting curve analysis to confirm specific amplifications.

2.10. Neurite Outgrowth Assay. PC12 cells were treated with SBL or NGF for 72 hours. A light microscope (Diagnostic Instruments, Sterling Heights, MI) equipped with a phasecontrast condenser (Zeiss), 10X objective lens, and a digital camera (Diagnostic Instruments) was used to capture the image with manual setting. For analyzing the number and length of neurite, approximately 100 cells were counted from at least 10 randomly chosen visual fields for each culture. Using the Photoshop software, the number and length of neurite were analyzed. The cells were scored as differentiated if one or more neurites were longer than the diameter of the cell body, and they were also classified into different groups according to the lengths of neurites, which are $<15 \mu \mathrm{m}, 15-$ $30 \mu \mathrm{m}$, and $>30 \mu \mathrm{m}$.

2.11. Western Blot Analysis. After the indicated time of treatment, cultures were collected in the high salt lysis buffer (10 mM HEPES, pH 7.5, $1 \mathrm{M} \mathrm{NaCl}, 1$ mM EDTA, 1 mM EGTA, $0.5 \%$ Triton $\mathrm{X}-100,5 \mathrm{mM}$ benzamidine $\mathrm{HCl}, 10 \mu \mathrm{M}$ aprotinin, $10 \mu \mathrm{M}$ leupeptin) and were analyzed immediately or stored frozen at $-20^{\circ} \mathrm{C}$. Proteins were separated on the $8 \%$ SDSpolyacrylamide gels and transferred to the nitrocellulose membrane. Successful transfer and equal loading of samples were confirmed by staining Ponceau-S. The nitrocellulose membrane was blocked with $5 \%$ fat-free milk in TBS-T 
TABLE 1: Chemical composition of volatile oil from NRR.

\begin{tabular}{|c|c|c|c|}
\hline Retention time $(\mathrm{min})$ & Compound $^{\mathrm{a}}$ & Molecular weight & RA $(\%)^{\mathrm{b}}$ \\
\hline 8.34 & $\beta$-maaliene & 204 & 7.9 \\
\hline 8.62 & 9-aristolene & 204 & 4.7 \\
\hline 9.08 & Calarene & 204 & 37.9 \\
\hline 9.29 & $\alpha$-maaliene & 204 & 1.2 \\
\hline 9.58 & Guaia-6,9-diene & 204 & 0.7 \\
\hline 9.77 & Valerena-4,1(11)-diene & 204 & 6.6 \\
\hline 10.79 & $\alpha$-humulene & 204 & 1.6 \\
\hline 12.49 & Epi- $\alpha$-selinene & 204 & 1.5 \\
\hline 14.64 & $\beta$-lonone & 192 & 2.1 \\
\hline 15.08 & 4-epi- $\alpha$-maaliol & 222 & 1.9 \\
\hline 19.24 & Patchouli alcohol & 222 & 5.5 \\
\hline 19.68 & Guaina-6,9-diene- $4 \beta$ ol & 220 & 3.7 \\
\hline 22.44 & Eudesma-3,11-dien-2-one & 218 & 1.7 \\
\hline 23.93 & Aristolone & 218 & 2.1 \\
\hline
\end{tabular}

${ }^{\mathrm{a}}$ The identified constituents are listed in their order of elution.

${ }^{\mathrm{b}} \mathrm{RA}$ indicates relative amount (peak area relative to the total peak area).

The extraction efficiency of NRR oil was over $95 \%$ within the 4 hours of distillation. In addition, the amount of extracted oil was $2.1 \pm 0.28 \%(n=4)$. The values are in mean of three individual experiments $(n=3)$. The SD values were less than $5 \%$ of the mean, not shown for clarity.

(20 mM Tris base, $137 \mathrm{mM} \mathrm{NaCl}, 0.1 \%$ Tween-20, $\mathrm{pH}$ 7.6) for 2 hours at room temperature, and then it was incubated in the primary antibody diluted in $2.5 \%$ fat-free milk in TBS$\mathrm{T}$ for 16 hours at $4^{\circ} \mathrm{C}$. The primary antibodies used were antiNF200 (Sigma), antiNF160 (Sigma), antiNF68 (Sigma), and antiGAPDH (Calbiochem, Germany). After that, the nitrocellulose was rinsed with TBS-T and incubated for 2 hours at the room temperature in horseradish peroxidase conjugated goat antimouse secondary antibody (Invitrogen) diluted in the $2.5 \%$ fat-free milk in TBS-T. After intensive washing with TBS-T, the immune complexes were visualized using the enhanced chemiluminescence (ECL) method (GE Healthcare, Piscataway, NJ). The intensities of the bands in the control and different samples were run on the same gel and under strictly standardized ECL conditions and compared on an image analyzer using a calibration plot constructed from a parallel gel with serial dilutions of one of the samples.

2.12. Other Assays. The protein concentrations were measured routinely by Bradford's method with kit from BioRad Laboratories (Hercules, CA). Statistical tests were done by using one-way analysis by student's $t$-test on Prism 4.00. Differences from basal or control values (as shown in the plots) were classed as significant $\left({ }^{*}\right)$ where $P<0.05,\left({ }^{* *}\right)$ where $P<0.01$.

\section{Results}

3.1. Chemical Analysis of $S B L$. According to the ancient method of preparation, two extracts were obtained from NRR extraction: (i) NRR extract without volatile oil, that is, NRR extract; and (ii) NRR plus volatile oil, that is, SBL. Both NRR and oil extracts were chemically standardized. The volatile oil from NRR was analyzed by GC-MS: 14 components were identified, which accounted for $79.1 \%$ of the total volatile oil. The amount of volatile oil within NRR was $2.1 \pm 0.28 \%$ $(n=4)$, and the relative amounts of each chemical were given (Table 1). The major components of the oil were calarene (37.9\%), $\beta$-maaliene (7.6\%), and 9-aristolene (5.1\%). Thus, a standardized NRR volatile oil should contain at least the chemicals as stated here. To standardize the water extract of NRR, HPLC fingerprint was generated. The amount of NRR extract from crude herb was $13.34 \pm 0.45 \%(n=4)$. The fingerprints of five different batches of NRR extract were compared, and this showed the consistence of the herbal extract (Figure 1). Ferulic acid and linarin were determined as chemical markers: these chemicals were reported to have known biological functions as described previously [1921]. The quantification of chemical markers was carried out by measuring the peak area according to the regression equation (see Table 1 in Supplementary Material available online at http://dx.doi.org/10.1155/2013/687958). Using the established HPLC method, the calibration curves of ferulic acid and linarin exhibited good linearity within a specific range of concentration. The correlation coefficients $\left(r^{2}\right)$ of those chemical markers were higher than 0.999. The limit of detection (LOD) and limit of quantification (LOQ) were determined at $\mathrm{S} / \mathrm{N}$ of 3 and 10 , respectively (Supplementary Table 1). The precision and repeatability of the chemical measurement were excellent, having a relative standard deviation (RSD) $<5 \%$ (Supplementary Table 2). The recovery experiment was carried out to evaluate the method accuracy. The recoveries of ferulic acid and linarin were $99.31 \%$ and $100.12 \%$, respectively. Thus, the employed HPLC method was validated by in performing the quantitative analysis. Here, we recommended that a standardized NRR extract should 


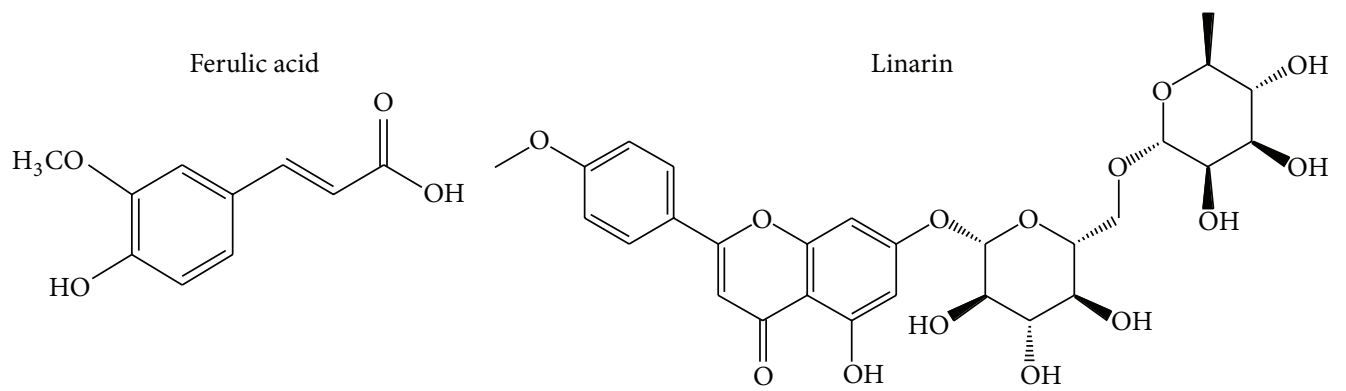

(a)

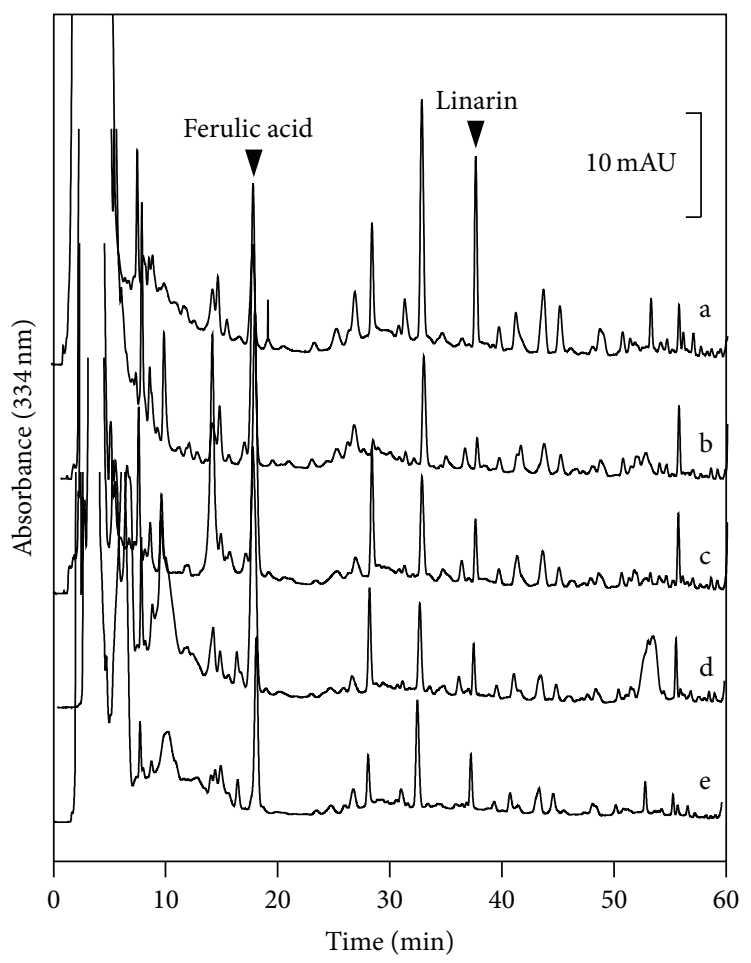

(b)

FIGURE 1: Chemical standardization of SBL by HPLC fingerprint analysis. Chemical structures of ferulic acid and linarin were shown (a). In the HPLC chromatogram at an absorbance of $334 \mathrm{~nm}$ (b), the peaks corresponding to ferulic acid and linarin in SBL are indicated by arrowheads. The fingerprints of different batches of NRR extracts (a-e) that were collected from (a) Songpan, (b) Abei, (c) Hongyuan, (d) Wing Lee Hong (HK), and (e) Wong Chak Kee (HK) of China are shown. The chromatographic method was described in Section 2. Representative chromatograms are shown, $n=3$.

contain at least $24.8 \mu \mathrm{g}$ ferulic acid and $114.9 \mu \mathrm{g}$ linarin in $1 \mathrm{~g}$ of dried NRR extract. A well-standardized SBL was prepared with the mixture of NRR extract and volatile oil in a ratio of 6 (NRR water extract; w) : 1 (NRR volatile oil; v).

3.2. SBL on tBHP-Treated PC12 Cells. To elucidate the function of NRR extract and SBL, the herbal extract was applied onto cultured PC12 cells. Firstly, the concentrations (3-12 $\mu \mathrm{g} / \mathrm{mL})$ of applied SBL did not show cytotoxicity or proliferating effect on the cultures (Supplementary Figure 1). The cell viability, determined by MTT assay, was significantly decreased by tBHP in dose-dependent manner (Figure 2(a)). Cultured PC12 cells were pretreated with SBL $(3-12 \mu \mathrm{g} / \mathrm{mL})$ for 24 hours before the challenged tBHP. Higher concentrations ( 6 and $12 \mu \mathrm{g} / \mathrm{mL}$ ) of SBL showed significant protection effect against the tBHP-induced cell death (Figure 2(b)). The applications of NRR extract $(6 \mu \mathrm{g} / \mathrm{mL})$ and volatile oil $(2 \mu \mathrm{g} / \mathrm{mL})$ in the cultures did not show any effect. Higher dose of NRR extract $(12 \mu \mathrm{g} / \mathrm{mL})$ showed the protection effect which, however, was lower than that of SBL (Figure 2(b)). Thus, the protection effect of SBL was better than that of NRR extract and volatile oil. The tBHP-induced cell mortality in PC12 cells was markedly reduced by the pretreatment of vitamin C, a positive control (Figure 2(b)).

The formation of ROS is one of the crucial causes in inducing neuronal cell death. By determining the formation of ROS in tBHP-treated PC12 cells, the role of SBL was 


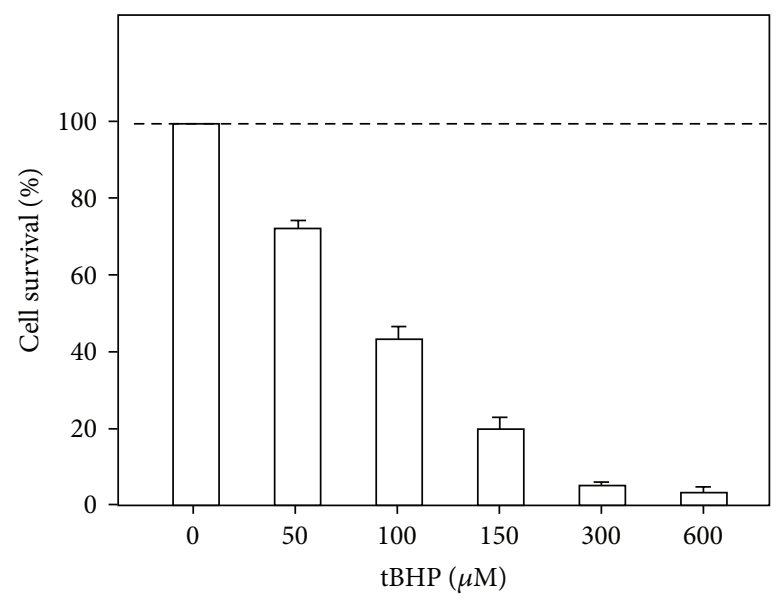

(a)

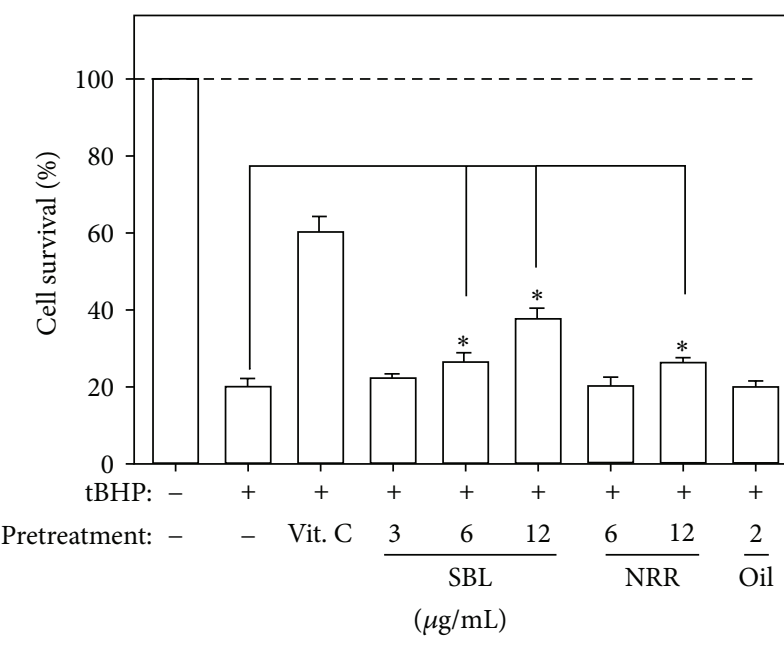

(b)

Figure 2: SBL prevents cell death in tBHP-treated PC12 cells. (a) Cultured PC12 cells were treated with tBHP (0-600 $\mu \mathrm{M})$ for 3 hours to determine the cytotoxicity of tBHP by cell viability assay. (b) PC12 cells were pretreated with SBL $(3-12 \mu \mathrm{g} / \mathrm{mL}), \mathrm{NRR}(6 \mathrm{and} 12 \mu \mathrm{g} / \mathrm{mL})$ and volatile oil $(2 \mu \mathrm{g} / \mathrm{mL})$ for 24 hours before the addition of tBHP $(150 \mu \mathrm{M})$ for 3 hours. The neuroprotective effect of SBL by cell viability assay was shown. Vitamin C $(1 \mathrm{mM})$ served as a positive control. The viability of PC12 cells is shown in percentage of MTT value relative to normal control. Data are expressed as Mean \pm SEM, where $n=5$, each with triplicate samples. ${ }^{*} P<0.05$ and ${ }^{* *} P<0.01$ as compared to the group (with tBHP alone).

analyzed. Application of tBHP in cultured PC12 cells induced the ROS formation in dose-dependent manner (Figure 3(a)). The tBHP-induced ROS formation was reduced by $\sim 25 \%$ after the pretreatment of $\mathrm{tBHQ}$, a known antioxidant. SBL, NRR extract and volatile oil were applied for 24 hours before the addition of tBHP $(100 \mu \mathrm{M})$, and then the cultures were subjected to the determination of intracellular ROS formation. Pretreatment of SBL reduced tBHP-induced ROS formation in dose-dependent manner: the maximal reduction at $\sim 40 \%$ was revealed after the treatment of $12 \mu \mathrm{g} / \mathrm{mL}$ SBL (Figure 3(b)). Although NRR extract (12 and $6 \mu \mathrm{g} / \mathrm{mL}$ ) showed the reduction effect in ROS formation, compared with SBL, the reduction efficacy was not as good as SBL. Pretreatment of volatile oil $(2 \mu \mathrm{g} / \mathrm{mL})$ did not show any reduction effect.

ARE is a cis-acting regulatory element or enhancer sequence, which is found in promoter regions of genes encoding detoxifying enzymes and antioxidant proteins [12]. To study the signaling mechanism of SBL in neuroprotection, the transcriptional activity of ARE, triggered by SBL, was studied. PC12 cells were stably transfected with a promoterreporter construct containing four repeats of ARE tagged with luciferace reporter gene (pARE-Luc) (Figure 4(a)). The pARE-Luc stably transfected PC12 cells were treated with SBL, NRR extract, and volatile oil for 24 hours, and then the cell lysates were collected to determine the luciferase activity. The application of SBL increased the transcriptional activity of pARE-Luc in dose-dependent manner, in which the maximal induction at $\sim 5$-fold was revealed at $12 \mu \mathrm{g} / \mathrm{mL}$ SBL (Figure 4(a)). NRR extract showed similar gene activation but at lower extend. NRR volatile oil could not increase the luciferase activity (Figure 4(a)). Based on the results of
pARE-Luc activation, we investigated the role of SBL in the expression of detoxifying enzymes that were stimulated by the responsive element ARE. The ARE-derived genes, including GST, GCLC, GCLM, and NQO1, were investigated via real-time $\mathrm{qPCR}$. Cultured PC12 cells were treated with SBL $(12 \mu \mathrm{g} / \mathrm{mL})$ for 24 hours. The levels of GST and GCLC mRNA were increased by $\sim 3$-fold with treatment of SBL. The expression level of GCLC was increased by $\sim 2$-fold. In the regulation of NQO1 expression, SBL showed a robust induction of NQO1 mRNA by over $\sim 4$-fold (Figure 4 (b)). This gene induction was better than that of $\mathrm{BHQ}(3 \mu \mathrm{M})$, a positive control.

3.3. SBL on the Differentiation of PC12 Cells. Neuronal differentiation effect of SBL on cultured PC12 cells was analyzed. After the treatment of NGF $(50 \mathrm{ng} / \mathrm{mL})$, the morphological change was observed. Longer neurites were protruded from the cell bodies (Figure 5(a)). This NGF treatment resulted in a $100 \%$ conversion of differentiated cells containing significant extension of neruites (Figure 5(b)). To evaluate the efficacies of SBL on PC12 differentiation, cells were treated with SBL $(12 \mu \mathrm{g} / \mathrm{mL})$ for 72 hours to induce a slight increase of neurite outgrowth with a conversion of differentiated cell by $\sim 20 \%$ (Figures 5(a) and 5(b)). Here, we aimed to determine the treatment of SBL together with low dose of NGF. A low concentration of NGF at $0.5 \mathrm{ng} / \mathrm{mL}$ failed to induce the neurite extension (Figure 5(a)). However, the cotreatment of SBL with low dose of NGF significantly potentiated the number of differentiated cell (at $\sim 60 \%$ ) as well as the neurite outgrowth (Figure 5(b)).

The SBL-induced neurofilament expression was also determined. After the treatment of SBL for 72 hours, the cells 


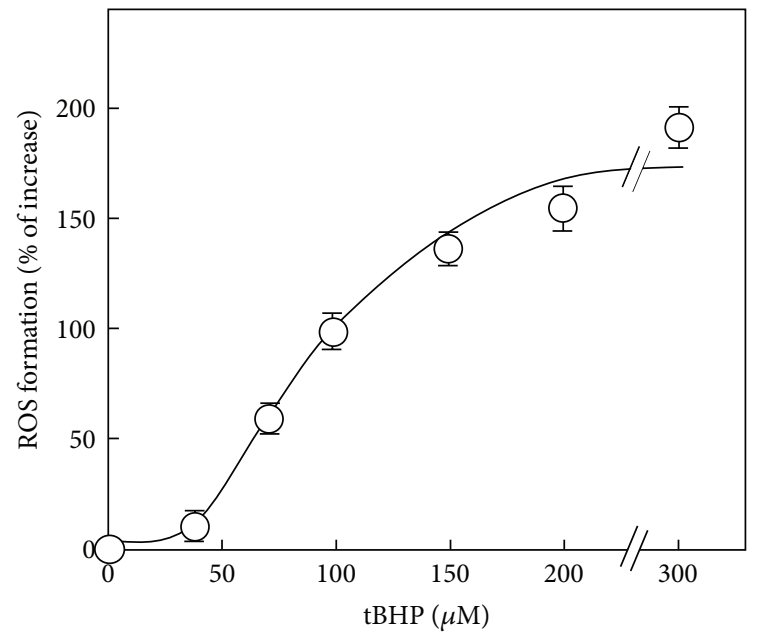

(a)

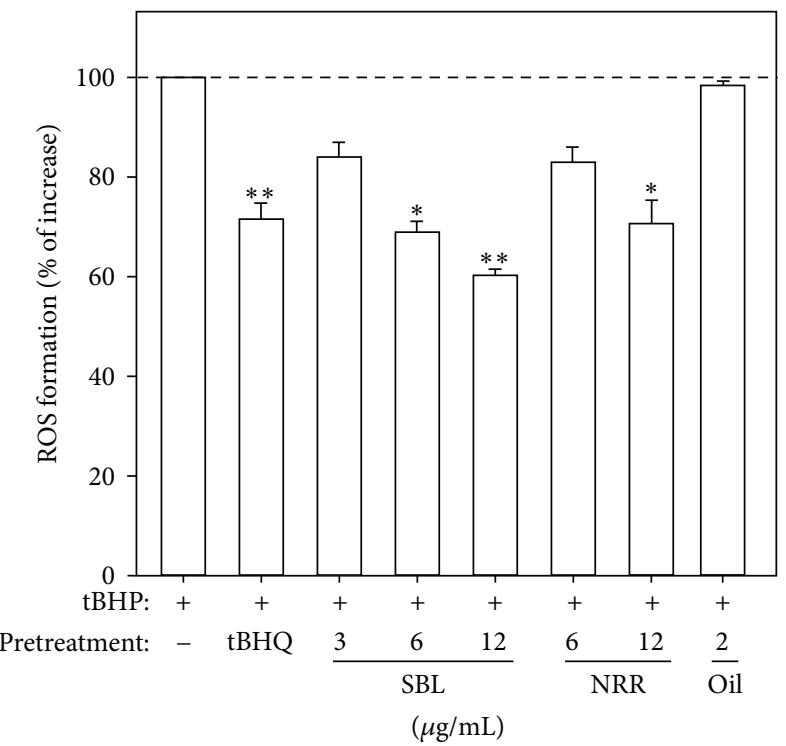

(b)

Figure 3: SBL suppresses the tBHP-induced ROS formation in PC12 cells. (a) Cultured PC12 cells were exposed to tBHP (0-300 $\mu$ M) for 1 hour. The level of intracellular ROS formation was measured by fluorescence method. The results are shown in percentage of increase in ROS formation relative to the control (without tBHP). (b) Cultured PC12 cells were pretreated with SBL (3-12 $\mu \mathrm{g} / \mathrm{mL}), \mathrm{NRR}(6 \mathrm{and} 12 \mu \mathrm{g} / \mathrm{mL})$, and volatile oil $(2 \mu \mathrm{g} / \mathrm{mL})$ for 24 hours and then exposed to tBHP $(100 \mu \mathrm{M})$ for 1 hour. The pretreatment of tBHQ $(3 \mu \mathrm{M})$ was used for comparison. The results are shown in percentage of ROS formation relative to the control (with tBHP alone). Data are expressed as Mean \pm SEM, where $n=5$, each with triplicate samples. ${ }^{*} P<0.05$ and ${ }^{* *} P<0.01$ as compared to the group (with tBHP alone).

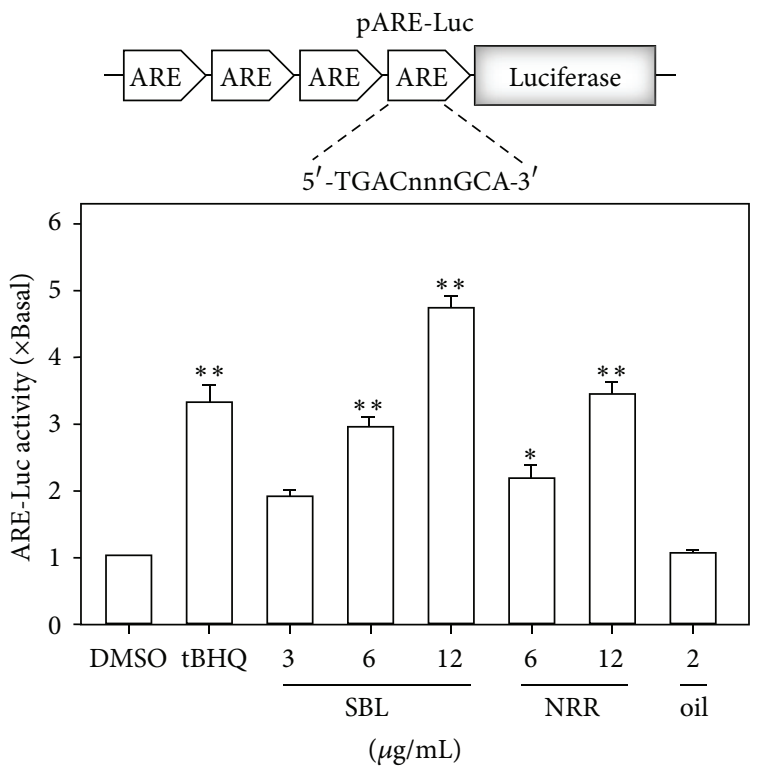

(a)

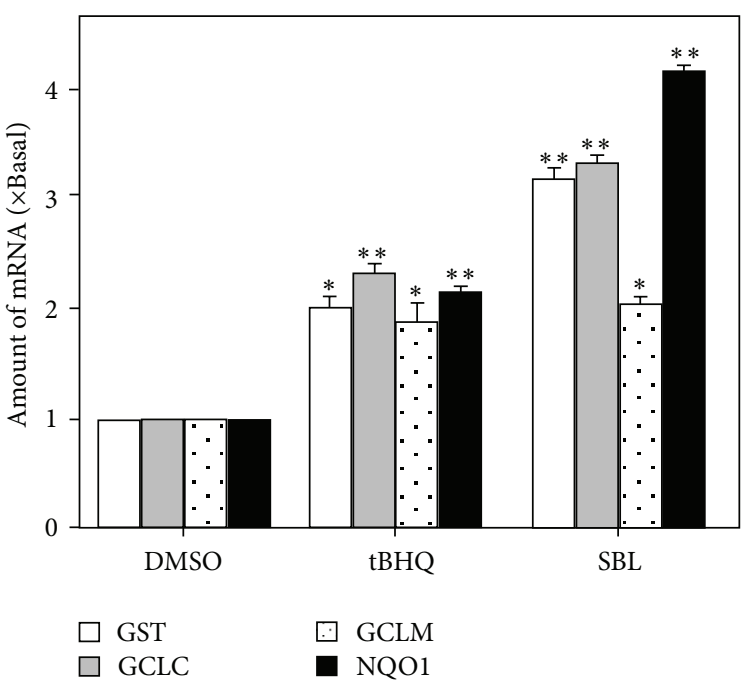

(b)

FIGURE 4: SBL induces ARE transcriptional activity and detoxifying enzymes in PC12 cells. (a) Four repeats of antioxidant responsive element (ARE: $5^{\prime}$-TGACnnnGCA-3') tagged with luciferase-reporter vector called pARE-luc (upper panel). This reporter was stably transfected to PC12 cells, which were treated with SBL, NRR, and volatile oil for 24 hours (lower panel). tBHQ ( $3 \mu \mathrm{M})$ was used as a positive control. (b) Cultured PC12 cells treated with SBL $(12 \mu \mathrm{g} / \mathrm{mL})$ and tBHQ $(3 \mu \mathrm{M})$ for 24 hours. Total RNAs were isolated from cultured PC12 cells and then reversed transcribed into cDNAs for the detection of mRNAs encoding for GST, GCLC, GCLM, and NQO1 by real-time PCR analysis. The GAPDH served as internal control. Values are expressed as the fold of increase to basal reading (untreated culture), and in Mean \pm SEM, where $n=4$, each with triplicate samples. ${ }^{*} P<0.05$ and ${ }^{* *} P<0.01$. 


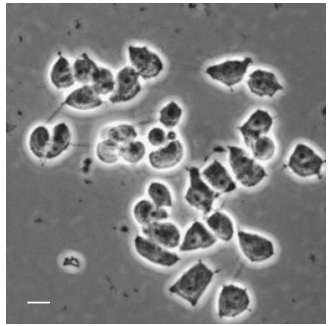

Control

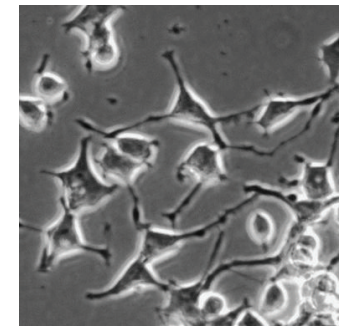

NGF $(50 \mathrm{ng} / \mathrm{mL})$

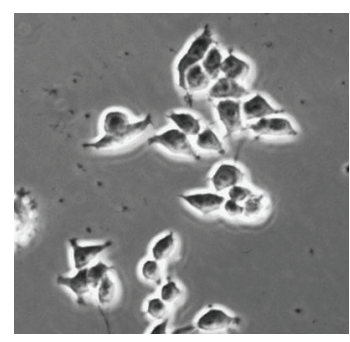

NGF $(0.5 \mathrm{ng} / \mathrm{mL})$

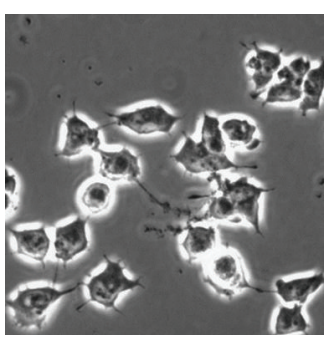

$\mathrm{SBL}(12 \mu \mathrm{g} / \mathrm{mL})$

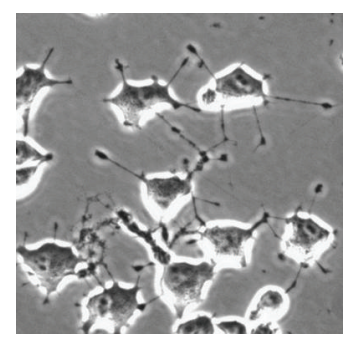

NGF $(0.5 \mathrm{ng} / \mathrm{mL})$ $\operatorname{SBL}(12 \mu \mathrm{g} / \mathrm{mL})$

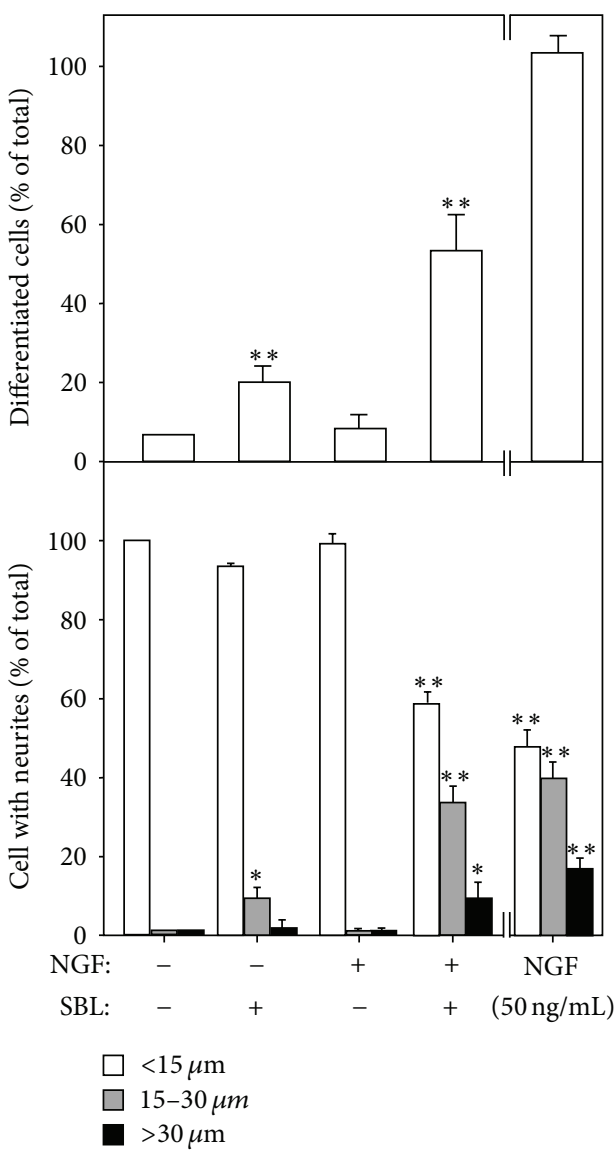

(b)

FIGURE 5: SBL potentiates the NGF-induced neurite outgrowth. (a) PC12 cells were treated with NGF $(0.5 \mathrm{ng} / \mathrm{mL} \mathrm{and} 50 \mathrm{ng} / \mathrm{mL}), \mathrm{SBL}$ $(12 \mu \mathrm{g} / \mathrm{mL})$, and NGF $(0.5 \mathrm{ng} / \mathrm{mL})+\mathrm{SBL}(12 \mu \mathrm{g} / \mathrm{mL})$ for 72 hours. The cultures were fixed, and extension of neurite outgrowth was revealed. Bar $=10 \mu \mathrm{m}$. (b) The $\%$ of differentiated cell (upper panel) and length of neurite (lower panel) were counted as described in Section 2. Values are expressed as $\%$ of cells in 100 counted cells. Mean \pm SEM, where $n=4 .{ }^{*} P<0.05$ and ${ }^{* *} P<0.01$ compared with control.

were collected to perform western blot analysis to determine the expressions of NF68, NF160, and NF200. By treatment of $12 \mu \mathrm{g} / \mathrm{mL}$ SBL, the expression of NF68 was increased by $\sim 5$-fold, while NF160 and NF200 were altered by $\sim 4$-fold (Figure 6). The induction of neurofilament was also revealed in the cotreatment of SBL with low dose of NGF. High dose of NGF, a positive control, showed robust protein induction. The expression of control protein GAPDH remained unchanged (Figure 6).

\section{Discussion}

SBL decoction is one of the simplest herbal medicinal preparations of TUM containing only one herb NRR. Based on TUM theory, SBL can be used to treat functional reduction of brain and heart caused by wet-cold and phlegm $[2,22]$. In line to ancient usage of SBL, here, we provided different lines of evidence to support the role of SBL in brain functions. First, SBL prevented the $\mathrm{tBHP}$-induced cell death, which most likely was mediated by a reduction of ROS formation. Second,
SBL induced the pARE-Luc activity as well as the gene activation of the key antioxidative stress proteins. Third, SBL induced differentiation of $\mathrm{PC} 12$ and the extension of neurites. More robustly, the cotreatment of SBL with NGF significantly induced the neuronal differentiation of $\mathrm{PC} 12$ cells. In parallel, the SBL-induced PC12 differentiation was shown to have a marked increase of neurofilament expression. These results strongly support the notion of SBL in treating neurasthenia clinically.

According to TUM practitioner's practice, two SBL preparation methods are performed in Xinjiang. The only difference between these two preparation methods is the collection of the vapor (i.e., volatile oil) during the boiling process. Indeed, NRR is well known to possess high amount of volatile oil [23]. To guarantee the consistency of SBL preparation chemically, we standardized both water extract and volatile oil of NRR. The amount of NRR extract and volatile oil within NRR by weight were $13.34 \%$ and $2.1 \%$, respectively. According to this ratio, NRR water extract and volatile oil were mixed together in the ratio of $6: 1(\mathrm{w}: \mathrm{v})$ to generate an authentic decoction of SBL. Here, we compared the biological 

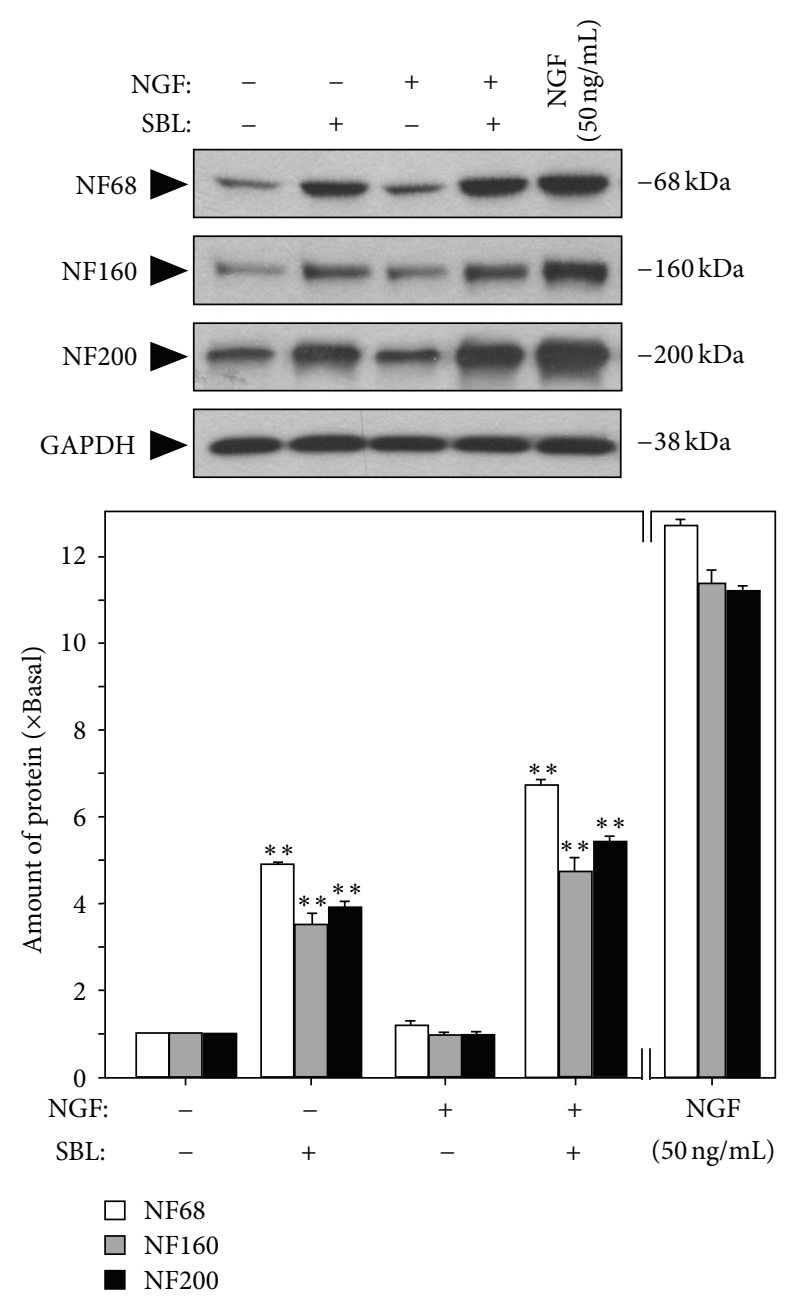

FIGURE 6: SBL potentiates the expression of neurofilaments. Cultured PC12 cells were treated with control, NGF $(0.5 \mathrm{ng} / \mathrm{mL}$ or $50 \mathrm{ng} / \mathrm{mL}), \mathrm{SBL}(12 \mu \mathrm{g} / \mathrm{mL})$, and NGF $(0.5 \mathrm{ng} / \mathrm{mL})+\mathrm{SBL}(12 \mu \mathrm{g} / \mathrm{mL})$ for 72 hours. The cultures were collected to determine the change of neurofilaments expression (NF68, NF160, and NF200). NGF at $50 \mathrm{ng} / \mathrm{mL}$ was set as the positive control. GAPDH served as a loading control. Representative images are shown (upper panel). The lower panel shows the quantification from the blots by a densitometer. Values are expressed as the fold of change (x Basal) against the control (no treatment; set as 1 ), and in Mean \pm SEM, where $n=4$.

efficacy of NRR extract, volatile oil, and SBL. Our results suggested that SBL in general showed better effects than that of NRR extract. Interestingly, volatile oil alone had no biological effect. This synergetic effect of volatile oil and NRR water extract was fully revealed in the case of SBL. Thus, a completed preparation (i.e., NRR water extract + volatile oil) of SBL is recommended for decoction preparation.

The redox-sensitive transcription factor NF-E2-related factor-2 (Nrf2) has been demonstrated to be a critical transcription factor that binds to antioxidant response element (ARE) in the promoter region of genes that code for phase II detoxifying enzymes in several types of cells. Activation of phase II detoxifying enzymes, such as GST, GCLM, GCLC, and NQO1, by phytochemicals resulted in detoxifying ROS
[24]. As demonstrated here, the antioxidative role of SBL could be in several aspects: (i) suppressing the formation of ROS, (ii) inducing the gene activation of pARE-Luc, and (iii) inducing antioxidative stress proteins. Amongst different antioxidative stress proteins, GST is involved in the detoxification of free radicals through catalyzing the conjugation of GSH: this is considered as one of the key enzymes associated with chemoprevention [11]. GSH is synthesized by the consecutive action of two enzymes, GCLC and GCLM [12]. Moreover, NQO1, a well-known Nrf2-ARE regulated enzyme, protects cells against deleterious reactive semiquinones by converting exogenous quinones into hydroquinones through two-electron reduction pathway [25]. Thus, the pretreatment of SBL protected the cells against oxidative-stress-induced cell death by scavenging ROS and activating the Nrf2-ARE self-defense mechanism.

Differentiation is a vital process for maturation of neuronal cells. When neurons differentiate, the neuron cell body (soma) would protrude long neurites in order to connect with other neurons to form synapses. Most of the neurological disorders are caused by the deficit of synaptic formation. During the neuronal differentiation, the expression level of neurofilaments and the neuronal cell specific cytoskeleton proteins, including 68,160, $200(\mathrm{kDa})$, were increased [14, 15]. In general, NF68 is expressed at the beginning of neurite outgrowth; then, NF160 is expressed shortly after with the emergence of neurite formation, and NF200 is expressed later when axonal radial growth is required for nervous system maturation. After the treatment of SBL, both neuron differentiation and expression of neurofilaments were promoted. More robustly, SBL showed a significant effect in potentiating the NGF-mediated neurite-inducing activity. A lot of neurological diseases are found to be associated with insufficiency of neurotropic factors, for example, depression [26] and Alzheimer's [27]. Neuronal cell death was found in depressed brain $[28,29]$. Additionally, ROS also caused the hippocampal neurons loss [30]. In depressed brain, the secretion of neurotrophic factors could be reduced, and the neuron could not survive, grow, or differentiate normally [31]. For the property of potentiation effect on NGF-mediated neurite outgrowth, SBL would have the potential to be used to treat the differentiation obstruction caused by NGF deficiency. Besides, our preliminary results also suggested the induction of various trophic factors by SBL in cultured astrocytes (data not shown).

Reports of antioxidant and neuroprotective effect of NRR have been published [32, 33]. Lyle et al. [34] reported that NRR alleviated the symptoms of chronic fatigue syndrome (CFS) with the role of antioxidant properties of NRR. Here, our results supported the notion that functional roles of SBL might be derived from its antioxidant properties. Phenolic components have strong antioxidant role as a hydrogen ion donor, and our colorimetric study showed that SBL extract contains relatively high amount of phenolic compounds. In addition, ferulic acid and linarin were shown to have protective effect on neurons $[19,21]$. In our study, ferulic acid and linarin showed promising effect in reducing the intracellular ROS formation (data not shown). On the other hand, the volatile oils of SBL are a mixture of lipids, terpenoids, ketones, 
and phenols. $\beta$-Maaliene, aristolene, and calarene, isolated from NRR, were reported to have a strong sedative and sleep enhancing activity [35]: these chemicals account for $57.1 \%$ of total volatile oil of SBL. Moreover, a partially purified glycoside from NRR was able to induce the outgrowth of neurites and the expression of growth-associated protein 43 (GAP-43) [36]. Thus, the distinctive properties of SBL could depend on the synergistic effects of total phenols, terpenoids, and/or other chemical components in SBL.

\section{Conclusion}

In summary, our study focused on the neuro-beneficial role of SBL, a simple ancient TUM, in cultured PC 12 cells. We found that pretreatment of a chemically standardized SBL could protect the cells from oxidative stress, which could be mediated by scavenging of ROS formation and stimulating the Nrf2-ARE self-defense mechanism. In addition, SBL could increase the expression of neurofilaments in cultured PC 12 cells and potentiated the NGF-mediated neurite outgrowth. Lastly, we demonstrated that the inclusion of volatile oil is necessary for a complete function of SBL. Taken together, these results partially revealed the action mechanism of SBL by cell studies.

\section{Acknowledgments}

This research was supported by the Hong Kong Research Grants Council Theme-based Research Scheme (T13$607 / 12 R$ ) and GRF (661110, 662911, 663012), and the Foundation of The Awareness of Nature (TAON12SC01) to KWKT.

\section{References}

[1] A. Yusup, H. Upur, I. Baudrimont et al., "Inhibition of cell growth and cellular protein, DNA and RNA synthesis in human hepatoma (HepG2) cells by ethanol extract of abnormal Savda Munziq of traditional Uighur medicine," Evidence-Based Complementary and Alternative Medicine, vol. 2011, Article ID 251424, 9 pages, 2011.

[2] M. Yishakejiang, K. Abudureyimu, and R. Abulake, China Medical Encyclopedia-Uyghur Medicine Volume, Shanghai Science and Technology Press, Shanghai, China, 2005.

[3] D. Maquet, C. Demoulin, and J.-M. Crielaard, "Chronic fatigue syndrome: a systematic review," Annales de Readaptation et de Medecine Physique, vol. 49, no. 6, pp. 418-427, 2006.

[4] Y. Cao, Y. Zhang, D. F. Chang, G. Wang, and X. Zhang, "Psychosocial and immunological factors in neurasthenia," Psychosomatics, vol. 50, no. 1, pp. 24-29, 2009.

[5] S. B. Harvey, S. Wessely, D. Kuh, and M. Hotopf, "The relationship between fatigue and psychiatric disorders: evidence for the concept of neurasthenia," Journal of Psychosomatic Research, vol. 66, no. 5, pp. 445-454, 2009.

[6] M. F. Beal, "Oxidatively modified proteins in aging and disease," Free Radical Biology and Medicine, vol. 32, no. 9, pp. 797-803, 2002.

[7] J. T. T. Zhu, R. C. Y. Choi, J. Li et al., "Estrogenic and neuroprotective properties of scutellarin from erigeron breviscapus: a drug against postmenopausal symptoms and alzheimer's disease," Planta Medica, vol. 75, no. 14, pp. 1489-1493, 2009.

[8] J. T. T. Zhu, R. C. Y. Choi, H. Q. Xie et al., "Hibifolin, a flavonol glycoside, prevents $\beta$-amyloid-induced neurotoxicity in cultured cortical neurons," Neuroscience Letters, vol. 461, no. 2, pp. 172-176, 2009.

[9] J. T. Coyli and P. Puttfarcken, "Oxidative stress, glutamate, and neurodegenerative disorders," Science, vol. 262, no. 5134, pp. 689-695, 1993.

[10] M. Ebadi, S. K. Srinivasan, and M. D. Baxi, "Oxidative stress and antioxidant therapy in Parkinson's disease," Progress in Neurobiology, vol. 48, no. 1, pp. 1-19, 1996.

[11] A. Pompella, A. Visvikis, A. Paolicchi, V. De Tata, and A. F. Casini, "The changing faces of glutathione, a cellular protagonist," Biochemical Pharmacology, vol. 66, no. 8, pp. 1499-1503, 2003.

[12] J. M. Lee and J. A. Johnson, "An important role of Nrf2ARE pathway in the cellular defense mechanism," Journal of Biochemistry and Molecular Biology, vol. 37, no. 2, pp. 139-143, 2004.

[13] S. Dhakshinamoorthy, A. K. Jain, D. A. Bloom, and A. K. Jaiswal, "Bach1 competes with Nrf2 leading to negative regulation of the antioxidant response element (ARE)-mediated $\mathrm{NAD}(\mathrm{P}) \mathrm{H}$ :quinone oxidoreductase 1 gene expression and induction in response to antioxidants," Journal of Biological Chemistry, vol. 280, no. 17, pp. 16891-16900, 2005.

[14] J. Schimmelpfeng, K.-F. Weibezahn, and H. Dertinger, "Quantification of NGF-dependent neuronal differentiation of PC12 cells by means of neurofilament-L mRNA expression and neuronal outgrowth," Journal of Neuroscience Methods, vol. 139, no. 2, pp. 299-306, 2004.

[15] S. L. Xu, R. C. Y. Choi, K. Y. Zhu et al., "Isorhamnetin, a flavonoid aglycone from Ginkgo biloba L., induces neuronal differentiation of cultured PC12 cells: potentiating the effect of nerve growth factor," Evidence-Based Complementary and Alternative Medicine, vol. 2012, Article ID 278273, 11 pages, 2012.

[16] M. K. Lee and D. W. Cleveland, "Neuronal intermediate filaments," Annual Review of Neuroscience, vol. 19, pp. 187-217, 1996.

[17] J. T. T. Zhu, R. C. Y. Choi, G. K. Y. Chu et al., "Flavonoids possess neuroprotective effects on cultured pheochromocytoma PC12 cells: a comparison of different flavonoids in activating estrogenic effect and in preventing $\beta$-amyloid-induced cell death," Journal of Agricultural and Food Chemistry, vol. 55, no. 6, pp. 2438-2445, 2007.

[18] J. Winer, C. K. S. Jung, I. Shackel, and P. M. Williams, "Development and validation of real-time quantitative reverse transcriptase-polymerase chain reaction for monitoring gene expression in cardiac myocytes in vitro," Analytical Biochemistry, vol. 270, no. 1, pp. 41-49, 1999.

[19] J. Kanski, M. Aksenova, A. Stoyanova, and D. A. Butterfield, "Ferulic acid antioxidant protection against hydroxyl and peroxyl radical oxidation in synaptosomal and neuronal cell culture systems in vitro structure-activity studies," Journal of Nutritional Biochemistry, vol. 13, no. 5, pp. 273-281, 2002.

[20] S. Fernández, C. Wasowski, A. C. Paladini, and M. Marder, "Sedative and sleep-enhancing properties of linarin, a flavonoid-isolated from Valeriana officinalis," Pharmacology Biochemistry and Behavior, vol. 77, no. 2, pp. 399-404, 2004.

[21] H. Lou, P. Fan, R. G. Perez, and H. Lou, "Neuroprotective effects of linarin through activation of the PI3K/Akt pathway in amyloid- $\beta$-induced neuronal cell death," Bioorganic and Medicinal Chemistry, vol. 19, no. 13, pp. 4021-4027, 2011. 
[22] J. N. Lu, "Study on the traditional Uyghur medicine Song $\mathrm{Bu}$ Li decoction," Journal of Medicine \& Pharmacy of Chinese Minorities, vol. 9, pp. 13-14, 2003.

[23] J. H. Wang, J. Zhao, H. Liu et al., "Chemical analysis and biological activity of the essential oils of two valerianaceous species from China: Nardostachys chinensis and Valeriana officinalis," Molecules, vol. 15, no. 9, pp. 6411-6422, 2010.

[24] J. A. Johnson, D. A. Johnson, A. D. Kraft et al., "The Nrf2ARE pathway: an indicator and modulator of oxidative stress in neurodegeneration," Annals of the New York Academy of Sciences, vol. 1147, pp. 61-69, 2008.

[25] D. Ross, J. K. Kepa, S. L. Winski, H. D. Beall, A. Anwar, and D. Siegel, "NAD(P)H:quinone oxidoreductase 1 (NQO1): chemoprotection, bioactivation, gene regulation and genetic polymorphisms," Chemico-Biological Interactions, vol. 129, no. 1-2, pp. 77-97, 2000.

[26] Y. Dwivedi, A. C. Mondal, H. S. Rizavi, and R. R. Conley, "Suicide brain is associated with decreased expression of neurotrophins," Biological Psychiatry, vol. 58, no. 4, pp. 315-324, 2005.

[27] S. Capsoni and A. Cattaneo, "On the molecular basis linking Nerve Growth Factor (NGF) to Alzheimer's disease," Cellular and Molecular Neurobiology, vol. 26, no. 4-6, pp. 619-633, 2006.

[28] H. K. Manji, W. C. Drevets, and D. S. Charney, "The cellular neurobiology of depression," Nature Medicine, vol. 7, no. 5, pp. 541-547, 2001.

[29] R. S. Duman, "Depression: a case of neuronal life and death?" Biological Psychiatry, vol. 56, no. 3, pp. 140-145, 2004.

[30] A. L. Lee, W. O. Ogle, and R. M. Sapolsky, "Stress and depression: possible links to neuron death in the hippocampus," Bipolar Disorders, vol. 4, no. 2, pp. 117-128, 2002.

[31] Y. Shirayama, A. C.-H. Chen, S. Nakagawa, D. S. Russell, and R. S. Duman, "Brain-derived neurotrophic factor produces antidepressant effects in behavioral models of depression," Journal of Neuroscience, vol. 22, no. 8, pp. 3251-3261, 2002.

[32] S. Salim, M. Ahmad, K. S. Zafar, A. S. Ahmad, and F. Islam, "Protective effect of Nardostachys jatamansi in rat cerebral ischemia," Pharmacology Biochemistry and Behavior, vol. 74, no. 2, pp. 481-486, 2003.

[33] M. B. Khan, M. N. Hoda, T. Ishrat et al., "Neuroprotective efficacy of Nardostachys jatamansi and crocetin in conjunction with selenium in cognitive impairment," Neurological Sciences, vol. 33, no. 5, pp. 1011-1020, 2012.

[34] N. Lyle, A. Gomes, T. Sur et al., "The role of antioxidant properties of Nardostachys jatamansi in alleviation of the symptoms of the chronic fatigue syndrome," Behavioural Brain Research, vol. 202, no. 2, pp. 285-290, 2009.

[35] H. Takemoto, T. Yagura, and M. Ito, "Evaluation of volatile components from spikenard: valerena-4,7(11)-diene is a highly active sedative compound," Journal of Natural Medicines, vol. 63, no. 4, pp. 380-385, 2009.

[36] J. H. Liu, F. Yin, and X. X. Zheng, "Nardostachys chinensis glycoside induces characteristics of neuronal differentiation in rat pheochromocytoma PC12 cells," Biological and Pharmaceutical Bulletin, vol. 28, no. 4, pp. 768-771, 2005. 


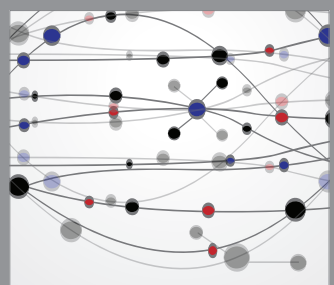

The Scientific World Journal
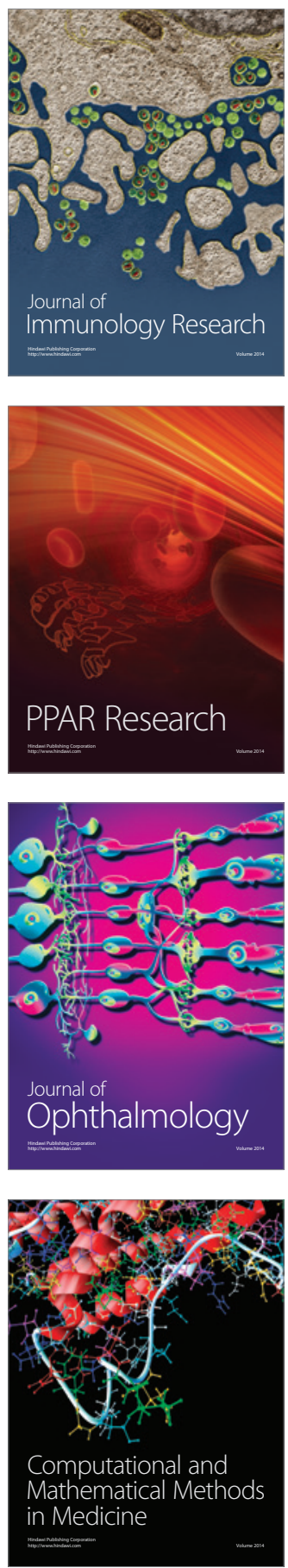

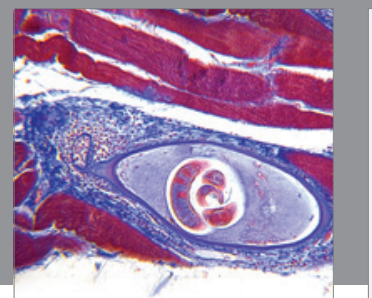

Gastroenterology

Research and Practice
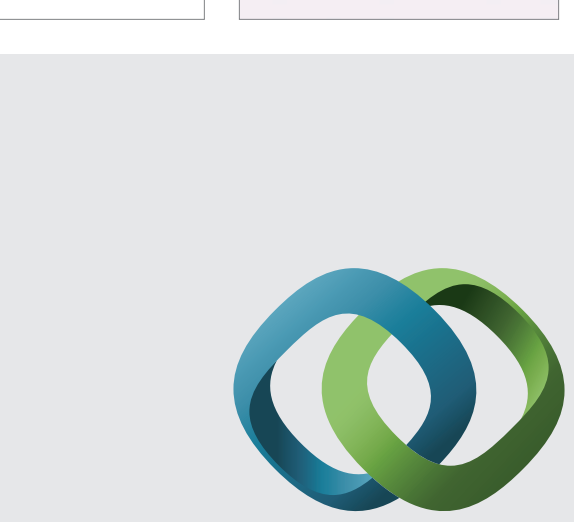

\section{Hindawi}

Submit your manuscripts at

http://www.hindawi.com
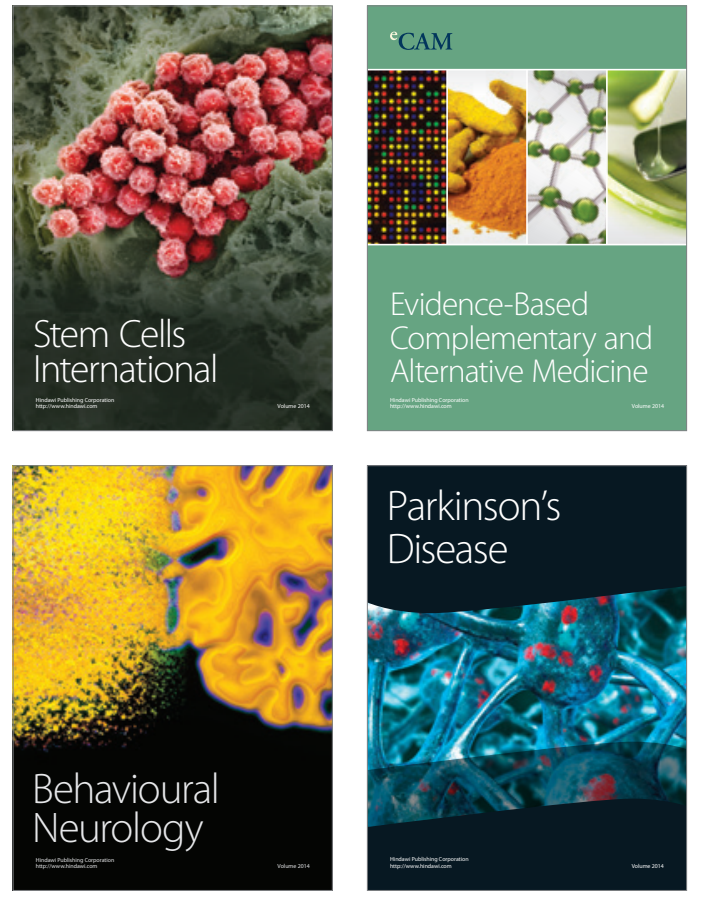
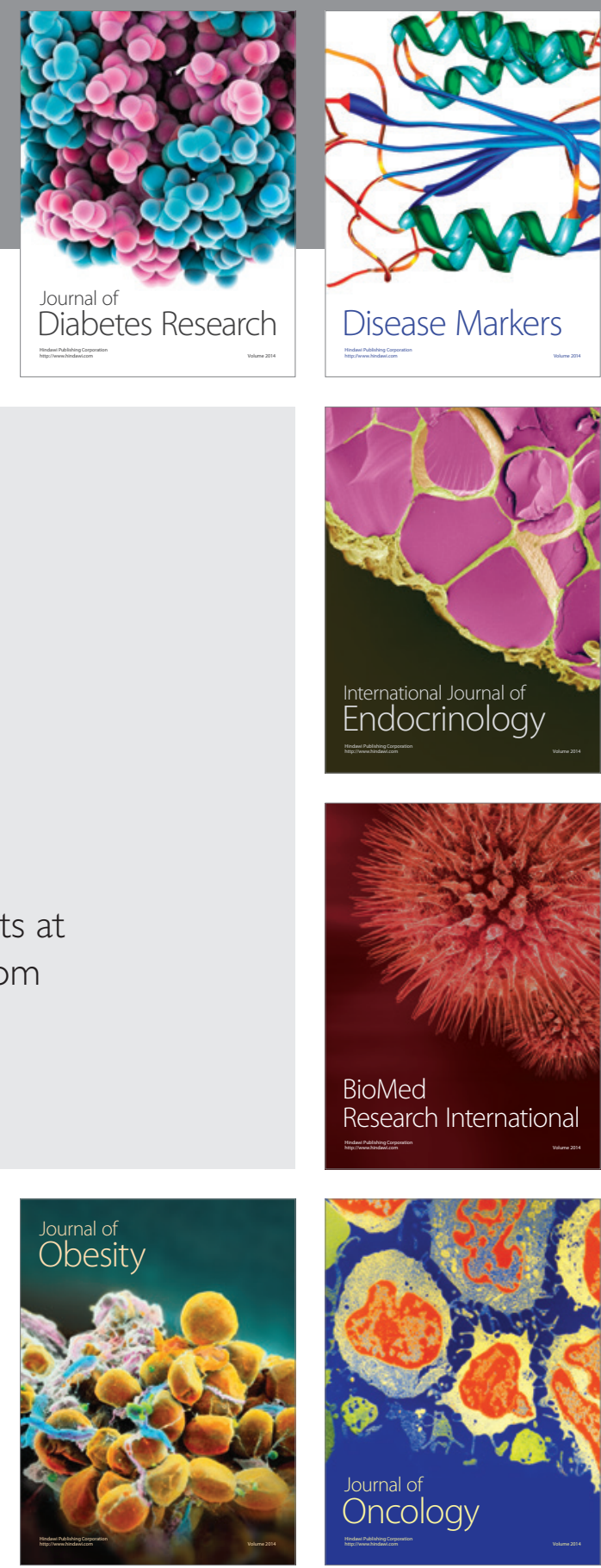

Disease Markers
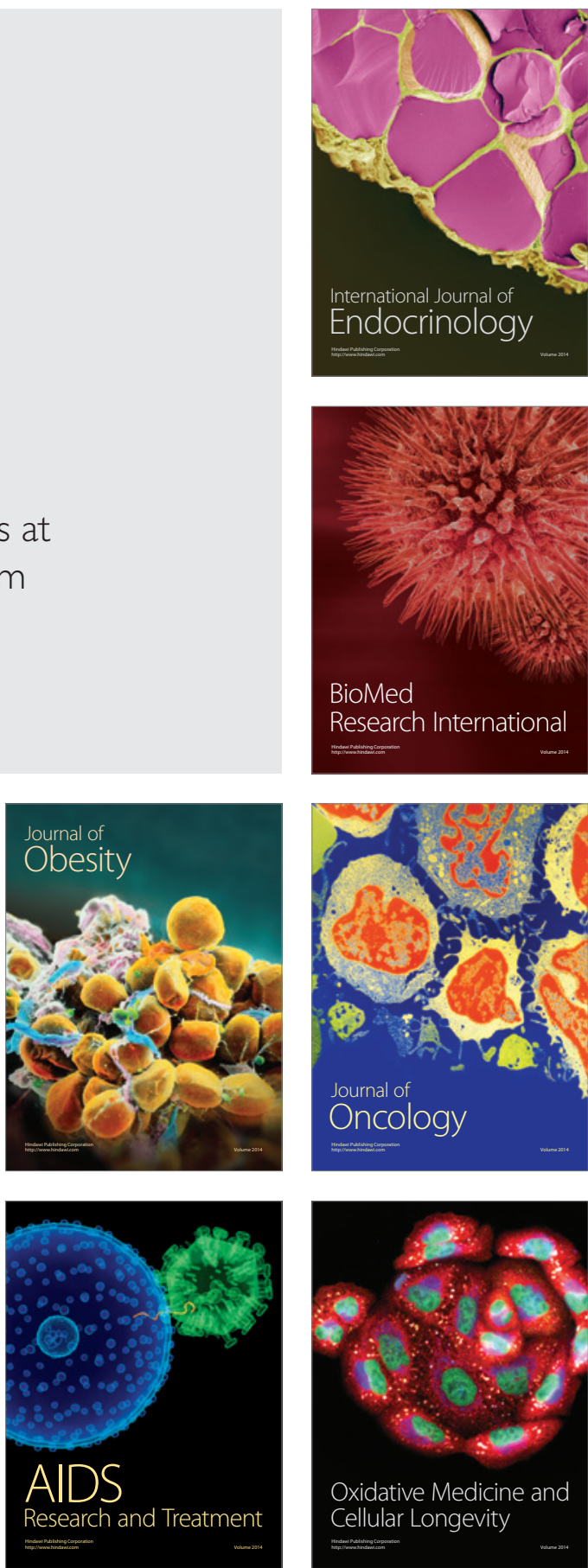